\title{
Incidence of leukaemia
}

SIR-There are several points in the letter by Crouch', concerning the paper by Forman et $a l .{ }^{2}$ on cancer near nuclear installations, that require comment.

First, Forman et al. employed cancer mortality data in their paper, rather than incidence data as suggested by Crouch, because "cancer registration data are of variable quality" (p.499).

Second, the observed excess of lymphoid leukaemia deaths in people under 25 years old is confined to what the authors term the "pre-1955 installation" grouping those establishments other than Sellafield that commenced nuclear operations before 1955. Indeed, Forman et al. state (p.501): "For lymphoid leukaemia there is a statistically increasing trend in RR [relative risk] with increasing proximity to an installation in the pre-1955 group (twosided $P=0.048$ ) and a significantly decreasing trend with increasing proximity to an installation for the grouped CEGB [Central Electricity Generating Board] installations (two-sided $P=$ $0.015) "$

The authors also note that this high relative risk associated with the pre-1955 installations is due, in large part, to particularly low numbers of observed deaths in the control areas, with which the installation areas are being compared.

Third, Crouch draws attention to radiation doses from the alpha-emitting isotopes of plutonium and americium in areas near Sellafield. The pre-1955 installations consist of the Amersham, Harwell, Springfields, Aldermaston and Capenhurst sites, and Forman et al. note (p.500) that "the activities carried out in these installations are heterogeneous". Springfields and Capenhurst are uranium-processing factories which do not handle transuranium radionuclides; ${ }^{3}$ Amersham does not discharge these elements and the nature of the processes at Aldermaston and Harwell are such that these two establishments release only small quantities of plutonium ${ }^{5}$. It is very unlikely that the observed excess of young lymphoid leukaemia deaths in this installation grouping could be due to emissions of these alpha-emitters.

In addition, Darby and Doll ${ }^{6}$ have found "no convincing evidence" (p.606) that the alpha-emitters released into the atmosphere by above-ground weapons tests have affected the leukaemia rates for this age group in either Britain or Scandinavia.

Considerable caution needs to be exercised in the interpretation of the patterns of leukaemia data near nuclear sites $^{7}$, particularly because mortality from other cancers is lower in the installation areas than in the control areas ${ }^{2}$. Areas around fossil-fuelled power stations (and suitable control areas) might provide a useful data set with which the results for nuclear installations could be compared ${ }^{8}$.

The impression that the associations found by Forman et al. represent causation could prove misleading. I doubt whether Crouch would see one of the benefits of CEGB nuclear reactors as protecting the local populations of young people against lymphoid leukaemia, even though this is what the data for this group of installations would appear superficially to suggest.

British Nuclear Fuels plc,

RICHARD WAKEFORD

Risley, Warrington,

Cheshire WA3 6AS, UK

1. Crouch, D. Nature 330, 319 (1987).

. Forman, D., Cook-Mozaffari, P., Darby, S., Davey, G. Stratton, I., Doll, R. \& Pike, M. Nature 329, 499-505 (1987)

3. British Nuclear Fuels plc. Annual report on radioactive discharges and monitoring of the environment 1986 (BNFL, Risley, 1987).

4. Hughes, J.S. \& Roberts, G.C. The radiation exposure of the UK population - 1984 review (NRPB-R173) (HMSO, London, 1984).

5. Dionian, J., Wan, S.L. \& Wrixon, A.D. Radiation doses to members of the public around AWRE Aldermaston, ROF Burghfield and AERE Harwell (NRPB-R202) (HMSO, London, 1987).

6. Darby, S.C. \& Doll, R. Br. med J. 294, 597-602 (1987)

7. Wakeford, R. Wilkie, D. \& Hargreaves, R. in Health effects of low dose ionising radiation (British Nuclear Energy Society, London, in press)

8. Baron, J.A. Br. J. Cancer 50, 815-824 (1984).

SIR-Although television current affairs programmes are not normally the most reliable source of information on controversial topics, I should like to draw the attention of David Crouch (Nature 330, $319 ; 1987)$ to a recent World in Action programme on child leukaemia.

Crouch asserts that child leukaemia "could indeed have been caused by radiation, and that we know of no other likely cause". Quoting an apparently reliable researcher in Newcastle, this television programme identified a 'super cluster' of excess child leukaemia in Gateshead, which is nowhere near a source of radiation.

36 Hill House Close,

William McMillan

Turners Hill,

West Sussex, UK

\section{Whiggishness}

SiR-I would like to add a vote for the 'pro-Butterfield' side of the debate on scientific whiggishness (Nature 329, 213: 1987).

Few would disagree that there are, for example, considerable differences between our scientific view of the world and that prevalent in ancient Egypt. These differences are unlikely to have come about overnight, old perspectives being discarded at the breakfast table. Our personal experience of a continuity of perspective suggests that such changes are of a more gradual evolution. Yet, like growing old, the subtlety of the change can blind us to its occurrence. Our modern perspective is not that of the nineteenth century, less that of the eighteenth, and it is uncertain how reliably one perspective can interpret another.

There is disagreement, even now, in matters of politics and religion. But a world view is a more profound level of perception than is membership in a political party. How can one truly understand a differing existential perspective in a more than rhetorical sense? One viewpoint is felt to be real and one necessarily lacks conviction - and without conviction it becomes no more than one pole of an argument.

Our science and our view of the world are closely interrelated. Even allowing the postulated Zen-like state where scientific history is chronicled with an 'empty rather than a full mind', the history of science is fraught with perils.

Department of Radiology,

Massachusetts General Hospital,

Boston, Massachusetts 02114, USA

\section{Soviet psychiatry}

SIR-I would like to correct a number of points in the article by Joseph Palca and Vera Rich on Soviet psychiatry (Nature 330, 684;1987).

Professor Aleksandr Snezhnevskii, who died recently, was the former head of the Institute of Psychiatry in Moscow, not of the Serbskii Institute of Forensic Psychiatry. He wrote widely on schizophrenia, much of the material being available in the West, and he never described all mental illness as a form of schizophrenia. His Handbook of Psychiatry (Meditsina, Moscow, 1983) covers the same range of topics as any Western psychiatric textbook. Incidentally, the chapter on schizophrenia in this book summarizes much of his previous work, and includes the criteria for diagnosing schizophrenia. $\mathrm{He}$ has never described political dissent as a form of "creeping schizophrenia". This notion has been perpetuated through ignorance or distortion of his work. There seems to be a basic failure to distinguish between the form and content of delusional thinking, a mistake which is common to students at the beginning of their psychiatric training.

Dialogue between Soviet and Western psychiatrists is going to be difficult while we continue seriously to misrepresent the views of a leading and highly respected Soviet psychiatrist.

S.P. Calloway

Fulbourn Hospital,

Cambridge Health Authority,

Fulbourn,

Cambridge CB1 5EF, UK 